\title{
Electromagnetic Compatibility Analysis of Substation Environment using Finite Difference Method
}

\author{
A. I. Tarmizi, R. H. Ramlee, Mihai D. Rotaru
}

\begin{abstract}
The implementation of the smart grid system transformed the old substation into a new automated substation. All equipment and component installed in the high voltage substation need to be electromagnetically compatible with each other. Thus, the magnetic field distributed in the environment must be predicted and quantified. Furthermore, with the use of more sensitive microelectronic devices in the system, it creates a need to reassess the substation environment compatibility for current and future circumstances. In this paper, the calculation method used to determine magnetic field distribution within a substation environment has been reviewed. A new routine which allows the user to focus at a specific area of the substation and calculate the field has been developed in-house using MATLAB. The new routine calculates the magnetic field using a finite difference approach and allows a much better field resolution to be achieved in a specific area of interest within the substation.
\end{abstract}

Keywords: Automated substation, Biot Savart Law, EMC, Finite Different Method, magnetic field, MATLAB, smart grid.

\section{INTRODUCTION}

In a smart grid system, there is a new level of expectation for distribution automation. Substation automation is expected to expand dramatically with increased control of relays, capacitor banks, and voltage regulators along the feeder. The smart grid substations are expected to incorporate distributed energy resources, advanced metering infrastructure, as well as demand response functions. Achieving these goals requires three essential components: 1. Intelligent Electronic Devices (IED) for sensing, measuring and control of the equipment and network parameters; 2. A communication network to connect different components; 3. Software applications at various levels of the network, including the substation system that can manage the other pieces of the automation system [1][3]. All the equipment or systems above need to function satisfactorily in its electromagnetic environment without introducing intolerable electromagnetic disturbances to anything in that environment [4], [5]. In a high voltage substation, while the components and equipment are operating, electric and magnetic fields are produced that might or might not cause interruption to the system; thus, it is crucial to make sure that the system is compatible and immune to electromagnetic interferences [6]-[8].

Electromagnetic compatibility (EMC) studies in the substation area are more concern today than ever before. Although the EMC issues have been discussed widely in

Revised Manuscript Received on September 14, 2019.

A. I. Tarmizi*, University of Southampton, UK, Universiti Teknikal Malaysia Melaka, UTeM. Email: aineizzati@utem.edu.my

R. H. Ramlee, Universiti Teknikal Malaysia Melaka, UTEM.
Mihai D. Rotaru, University of Southampton, UK.

power systems, there has been limited work done on the EMC within the current implementation of the automated substation, especially in the context of a smart grid [9]-[11]. Thus, it is significant that the electromagnetic field distribution within a substation environment is well identified with the intention of the possible to reduced EMC hazards. To have a clear view of the magnetic distribution, the previous researcher has done mapping of the field distributed via site measurements [12]-[14] or simulations [15], [16]. Deciding on which approach to use are depends on many factors; however, approaches, measurement and simulation have been used in previous research [17]-[19]. Since it is difficult and nearly impossible to measure the magnetic field distribution during disturbances occurrence computational methods are used to predict and illustrate the real event. As discussed in the previously published work, Biot-Savart law can be employed directly to solve the electromagnetic problem that has a large size environment. To simplify the computational complexity and improve the efficiency a coarse mesh was applied [20]. However, to understand the field intensity and its distribution where the sensitive equipment may be installed within the substation a better resolution of the field solution is necessary. In this paper, an extension of the previous work is provided. A methodology that allows details analysis on specific volumes in the substation environment based on the Finite Difference Method (FDM) is presented. The numerical algorithm has been developed in MATLAB and can perform a detailed analysis of the magnetic field distribution within the specific region in the substation environment. This is would be giving the user or utility company information on the electromagnetic environment at a specific location within the substation and informed decision where to install the new equipment can be taken.

\section{EMC LIMITATION GUIDELINES AND STANDARD}

Limits guidelines and standards used to ensure that the substation environment is safe for human health and the equipment able to operate compatibly in the substation environment system. From a health and safety point of view, these generated fields should be within the range of health regulations and EMC standards. The International Commission sets the majority of the national guidelines on Non-Ionizing Radiation Protection (ICNIRP) which is recognised by the World Health Organization (WHO) which

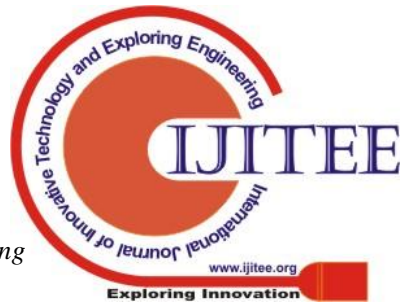


is a non-governmental organisation that assesses scientific outcomes from all over the world. The limits recommended by the ICNIPR and WHO for human exposure limits of the magnetic field are published to be $80 \mathrm{~A} / \mathrm{m}$ for public exposure and $400 \mathrm{~A} / \mathrm{m}$ for occupational exposure [21].

For this research study will be focusing on the standard that applied directly to the equipment limitation to magnetic field disturbances at medium voltage and high voltage substation environment. In the substation environment magnetic field is dependent on the configuration of the high voltage line, load, and fault condition. It is significant to know the field profile in the electromagnetic environment exposure towards equipment. Thus, the values of the magnetic field in the substation area from the standard will be used to compare the EMC as in Table I

Table- I: Values of the magnetic field in high voltage substation areas [22]

\begin{tabular}{|c|c|c|}
\hline Substation & $220 \mathrm{kV}$ & $400 \mathrm{kV}$ \\
\hline $\begin{array}{l}\text { Under the bus-bars } \\
\text { near the connection to a } \\
\text { line carrying about } 0.5 \\
\mathrm{kA}\end{array}$ & $14 \mathrm{~A} / \mathrm{m}$ & $9 \mathrm{~A} / \mathrm{m}$ \\
\hline $\begin{array}{l}\text { In the relay room } \\
\text { (kiosk) }\end{array}$ & \multicolumn{2}{|c|}{$\begin{array}{l}\text { Near event recorders at about } \\
0.5 \text { m distance: } 3.3 \mathrm{~A} / \mathrm{m} \\
\text { Near measurement voltage } \\
\text { transformer: } \\
\quad \mathrm{d}=0.1 \mathrm{~m}: 7.0 \mathrm{~A} / \mathrm{m} \\
\mathrm{d}=0.3 \mathrm{~m}: 1.1 \mathrm{~A} / \mathrm{m}\end{array}$} \\
\hline $\begin{array}{l}\text { In the equipment } \\
\text { room }\end{array}$ & \multicolumn{2}{|c|}{ Maximum $0.7 \mathrm{~A} / \mathrm{m}$} \\
\hline
\end{tabular}

\section{MAGNETIC FIELD CALCULATION USING FINITE DIFFERENCE METHOD}

To get a detailed analysis of a specific area in the substation, first, the coarse magnetic field distribution is computed using the methodology described in our previous work [20]. The volume of interest is then separated from the initial coarse solution, and a more detailed FDM is applied in this volume using the information already computed as the boundary condition. The details of this procedure are presented in the following sections.

A Mathematical Description of FDM Equation for Magnetic Field Calculation

FDM is a numerical computational method used to solve linear partial differential equations. As we are interested in the magnetic field distribution, we need to consider the Ampere's law stated in (1):

$$
\nabla \times \mathbf{H}=\mathbf{J}_{e}+\frac{\partial \mathbf{D}}{\partial t}
$$

$\mathbf{J}_{e}$ is the conduction current density and $\frac{\partial \mathbf{D}}{\partial t}$ is the displacement current density respectively. For the case study here the displacement current density is considered to be negligible as the main field is produced by the current flowing at $50 \mathrm{~Hz}$ the grid frequency If fault currents produce the magnetic field, currents due to switching or currents due to lighting strike their higher harmonics may produce displacements currents that cannot be ignored, hence the solution provided here is not applicable. However, if the displacement current is ignored, a quasistatic case can be assumed. Finally, using Faraday's law in (2) and Ohms law is written in its microscopical form in (3) one can rewrite in (1) as (4) which is an equation having one single variable namely magnetic field.

$$
\begin{gathered}
\nabla \times \mathbf{E}=-\mu_{\circ} \mu_{r} \frac{\partial \mathbf{H}}{\partial t} \\
\mathbf{J}_{e}=\sigma \mathbf{E}
\end{gathered}
$$

The new problem that needs to be solved now is a second-order differential in (4) which is known as diffusion equation.

$$
\nabla^{2} \mathbf{H}=\sigma \mu_{\circ} \mu_{r} \frac{\partial \mathbf{H}}{\partial t}
$$

In (4) can be written in three dimensions as follow.

$\left[\frac{\partial^{2}}{\partial x^{2}}+\frac{\partial^{2}}{\partial y^{2}}+\frac{\partial^{2}}{\partial z^{2}}\right] \mathbf{H}_{(x, y, z, t)}^{m}=\sigma \mu_{0} \mu_{r} \frac{\partial \mathbf{H}(x, y, z, t)}{\partial t}$

The finite difference approximation for the spatial component in (5) in the three axes $(x, y, z)$ is then:

$$
\begin{aligned}
& \frac{\partial^{2} \mathbf{H}_{(x, y, z)}^{m}}{\partial x^{2}}=\frac{\mathbf{H}_{(k+1, j, i)}-2 \mathbf{H}_{(k, j, i)}+\mathbf{H}_{(k-1, j, i)}}{\Delta x^{2}} \\
& \frac{\partial^{2} \mathbf{H}_{(x, y, z)}^{m}}{\partial y^{2}}=\frac{\mathbf{H}_{(k, j+1, i)}-2 \mathbf{H}_{(k, j, i)}+\mathbf{H}_{(k, j-1, i)}}{\Delta y^{2}} \\
& \frac{\partial^{2} \mathbf{H}_{(x, y, z)}^{m}}{\partial z^{2}}=\frac{\mathbf{H}_{(k, j, i+1)}-2 \mathbf{H}_{(k, j, i)}+\mathbf{H}_{(k, j, i-1)}}{\Delta z^{2}}
\end{aligned}
$$

Similarly, the finite difference approximation of the time component in (5) is shown in (9).

$$
\sigma \mu_{0} \mu_{r} \frac{\partial \mathbf{H}}{\partial t}=\sigma \mu_{0} \mu_{r} \frac{\mathbf{H}_{(k, j, i)}^{m+1}-\mathbf{H}_{(k, j, i)}^{m}}{\Delta t}
$$

If we let $\Delta x=\Delta y=\Delta z=\boldsymbol{h}$, the simplified equation can be written as follow.

$$
\begin{gathered}
\mathbf{H}_{(k, j, i)}^{m+1}=\mathbf{H}_{(k, j, i)}^{m}+C\left[\mathbf{H}_{(k+1, j, i)}^{m}-6 \mathbf{H}_{(k, j, i)}\right. \\
+\mathbf{H}_{(k-1, j, i)}+\mathbf{H}_{(k, j+1, i)} \\
+\mathbf{H}_{(k, j-1, i)}+\mathbf{H}_{(k, j, i+1)} \\
\left.+\mathbf{H}_{(k, j, i-1)}\right] \\
\mathbf{H}_{(0)}^{m+1}=\mathbf{H}_{(0)}^{m}+C\left[\mathbf{H}_{1}^{m}-6 \mathbf{H}_{0}^{m}+\mathbf{H}_{2}^{m}+\mathbf{H}_{3}^{m}+\mathbf{H}_{4}^{m}\right. \\
\left.+\mathbf{H}_{5}^{m}+\mathbf{H}_{6}^{m}\right]
\end{gathered}
$$

After further simplification, the final equation stated in (10) and the coefficient represented in (11) can be written as below.

$$
\begin{gathered}
\mathbf{H}_{0}=C\left(\mathbf{H}_{1}+\mathbf{H}_{2}+\mathbf{H}_{3}+\mathbf{H}_{4}+\mathbf{H}_{5}+\mathbf{H}_{6}\right) \\
C=\left(6+j \omega \sigma \mu_{0} h^{2}\right)^{-1}
\end{gathered}
$$

The application in (12) and (13) within the volume of 
interest area in the substation are illustrated in a uniform 3D mesh grid as in Fig. 1.

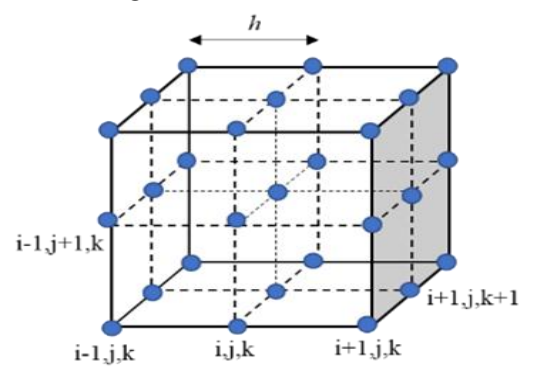

Fig. 1. Uniform mesh in 3-D grid point.

\section{B Substation Structure and Modelling Assumptions}

The layout of the substation used in this research is generously provided by the University of Cluj Romania, Faculty of Electrotechnics. The Rosiori substation is a $400 / 220 \mathrm{kV}$ substation and is a major substation of the National Power System (SEN), located in the north of Romania. The substation consists of a $400 \mathrm{kV}$ double busbar steps down to $220 \mathrm{kV}$ with three outgoing feeders [23]. One of the main reasons that this specific substation used in this research was the availability of magnetic and electric field measurements done by researchers in Cluj, Romania [7] which will be used to validate the developed calculation model. Fig. 2 shows that the computed results for the normal operating currents with the predicted highest value of the magnetic field are $4.164 \mathrm{~A} / \mathrm{m}$ which located along busbar 1 , where it is connected to Load 1, drawing a 200A current as published in [20].

By referring to the coarse calculation which refereeing to overall magnetic field distribution from the previous calculation for the whole substation with larger mesh grid in Fig. 2, the user chooses the volume of interest area as illustrated in Fig. 3. Once the volume of interest has been determined the size of the mesh has to be chosen. The details need to be plug-in the numerical calculation routine developed in MATLAB.

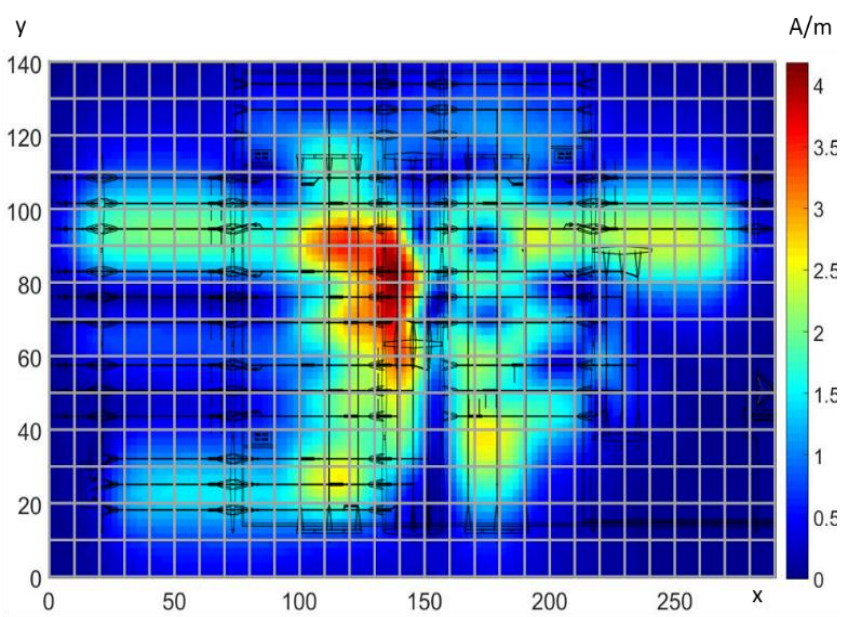

Fig. 2. The computed magnetic field (A/m)

distribution at the Rosiori substation (in grid square cell) at the height of $1.7 \mathrm{~m}$ above the ground.

The simulation model developed computes magnetic field within a volume of interest within the substation environment using the finite difference method in three dimensions (3D). The developed routine divides the subdomain of interest in cubic cells with space step of $\boldsymbol{h}$ as shown in Fig. 4. With this algorithm, the density of the calculation points can be easily modified to focus on regions of higher interest. The initial value of the calculated fields at the boundaries is assumed to be fixed due to the changes in the subdomain.

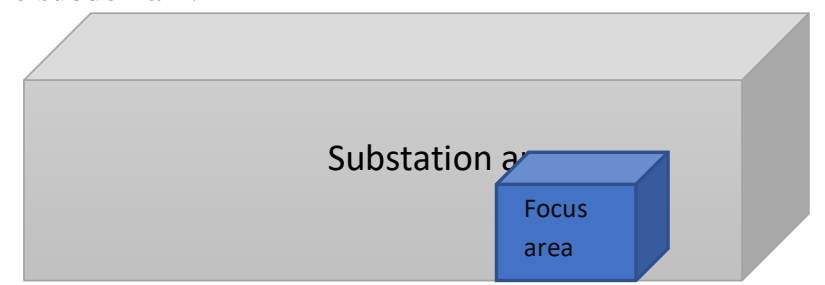

Fig. 3. Illustration of whole substation area and focus area.

\section{FDM CALCULATED RESULT AND COMPARISON WITH BSL CALCULATION METHOD}

The calculated magnetic field for focus area was calculated using finite difference method (FDM) as shown in Fig. 4 with the highest magnetic field were estimated to be nearly $5 \mathrm{~A} / \mathrm{m}$ which is below ICNIPR exposure guideline [24]. The FDM result was compared with the field calculated using Biot-Savart Law (BSL) [20] as plotted in Fig. 5 .

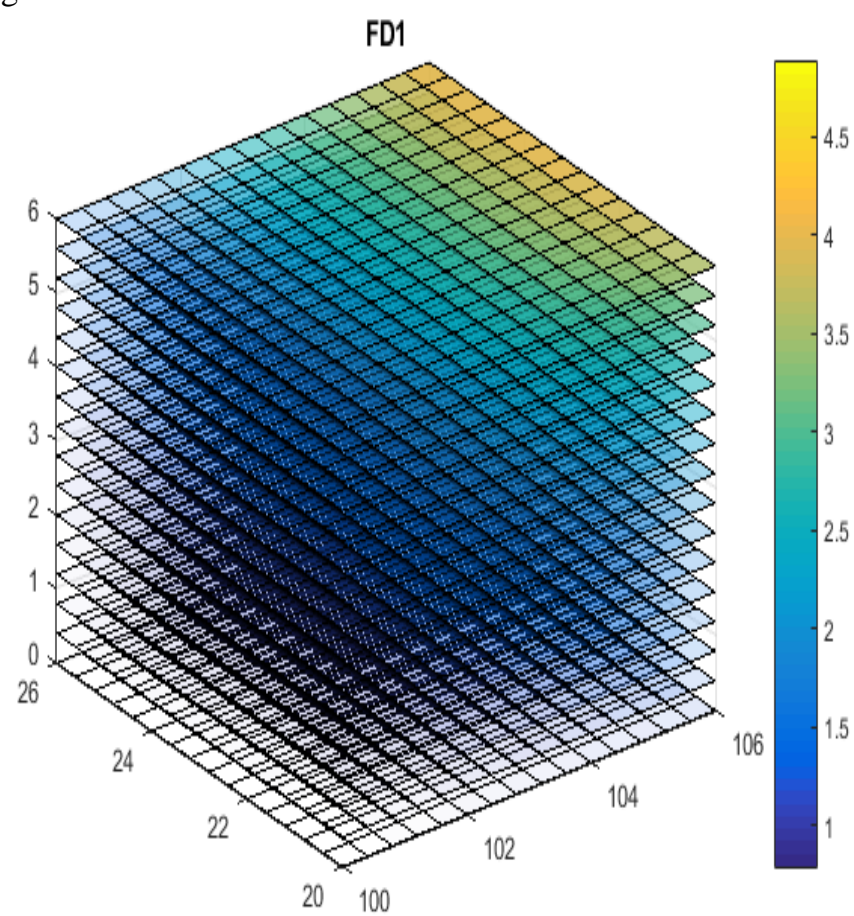

Fig. 4. Calculated magnetic field $(\mathrm{A} / \mathrm{m})$ at the focus area in the substation using Finite Difference Equation Method. 


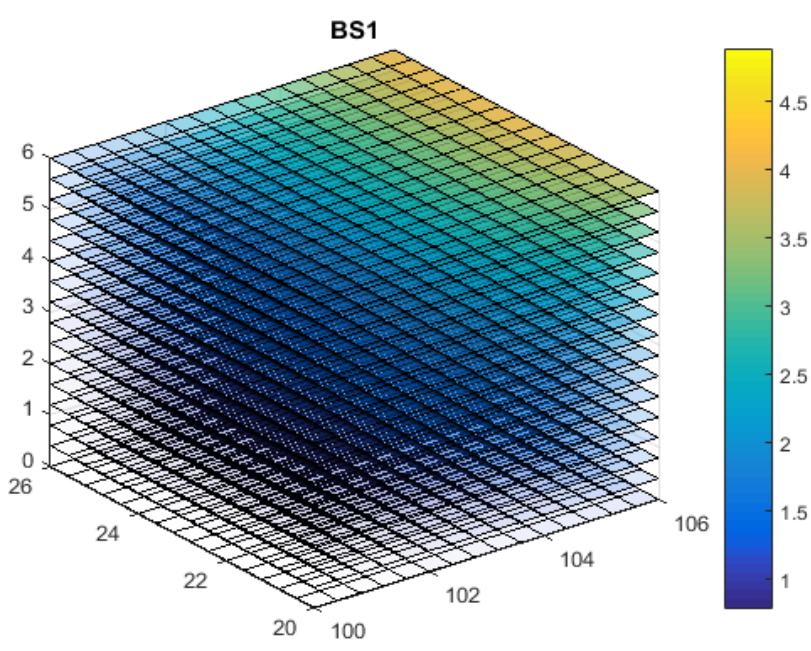

Fig. 5. Calculated magnetic field $(\mathrm{A} / \mathrm{m})$ at focus area in the substation using Biot Savart Law.

The algorithm calculates the magnetic field start from initial value towards the inside for the whole area with the resolution of $0.02 \mathrm{~m}$ for every axis $(\mathrm{x}, \mathrm{y}, \mathrm{z})$. From both figures, it shows that the calculated value of $\mathbf{H}$ for both methods is almost the same, and it is difficult to do the comparative analyses. Thus, to get a better view, the percentage difference of the magnetic field between both calculation methods was calculated.

The percentage differences for every point between FDM and BSL are calculated and plotted in Fig. 6. From the figure, it is clear that the initial magnetic field value which starts from outer points of the focus area is the same for both calculation methods with $0 \%$ difference.

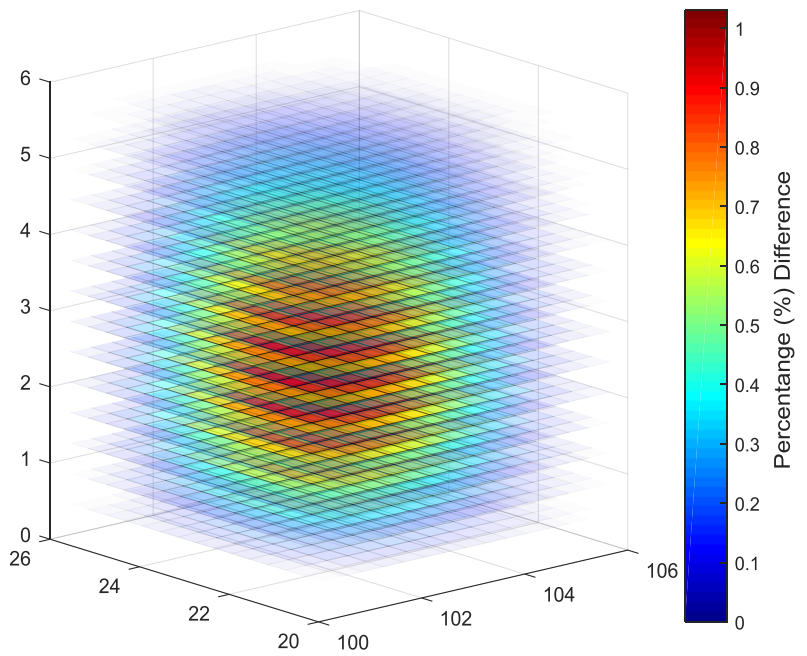

Fig. 6. The percentage indifferent between FDM and BSL.

The differences between both approaches are getting more prominent as it calculates far apart from the initial value. It is shown that the centre of the focus area has the highest with $1.01 \%$ percentage difference. To get a better view of the percentage difference between both numerical calculation methods, a cross-section of the focus area (Fig. 6) at $2.8 \mathrm{~m}$ ware plotted in Fig. 7 and Fig. 8. From both figures, it shows that the maximum value of percentage difference error is $1.012 \%$. The percentage difference for both calculation methods gradually increases as it calculates the magnetic field towards the centre of the area. With the low percentage of difference, it is confident that both numerical methods can predict the magnetic field.

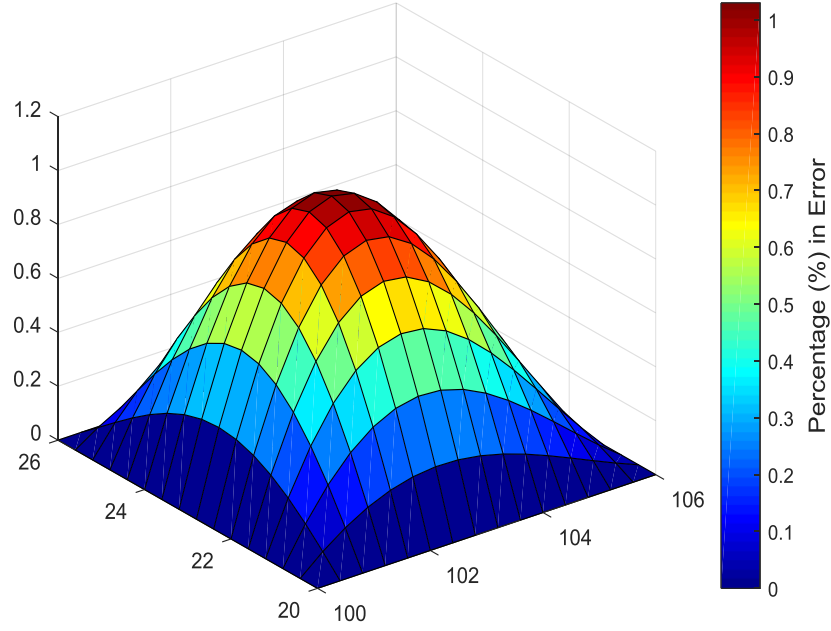

Fig. 7. Percentage difference at a cross-section of the focus area.

From the calculation result, there a few element comparisons that can be made between BSL and FDM. First, the BSL calculation takes more time to compute as the magnetic field was calculated directly from the source of current to the point of interest. The distance of the observation point to the conductor is changing. It is changing proportionally the calculated magnetic field induced by the current input. The calculation time could be reduced by setting the point of interest to be in a larger mesh. Thus, BSL is suitable to use to get an overall picture of the magnetic field distribution in the substation area with large mesh grid. In another hand, by using FDM, it can be used to predict the magnetic field by using the initial calculated value but for smaller grid mesh, which is needed to calculate for the whole focus area.

The combination of both calculation methods is the best for EMC studies in large substation area. It definitely will reduce the calculation time and the user able to choose the desired location with a preferable size of the mesh grid. Thus, it will allow the utility company to predict and determine the most suitable location to place the new equipment for the smart grid system.

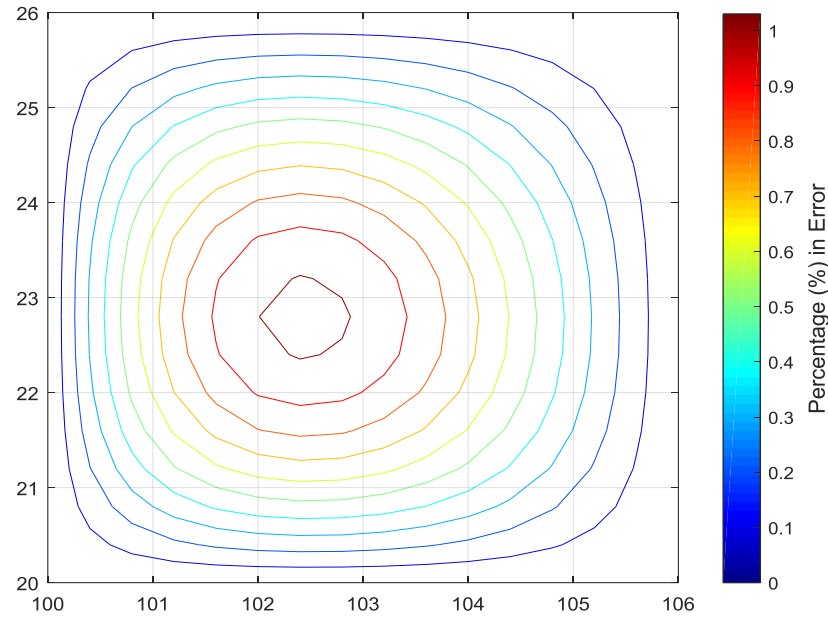

Fig. 8. Percentage difference at $\mathbf{2 . 8 m}$ cross-section of the focus area 


\section{INTRODUCTION OF A METAL BOX IN THE SUBSTATION ENVIRONMENT \& RESULTS}

There is another crucial justification to be made before installing new equipment in the substation. The equipment needs to be functional and connected to the substation within the optimum level and cost-friendly. To illustrate the real equipment that installs in the substation environment, a metal box model with holes which will demonstrate the cut off from the box for any connecting power supply and control buttons on the equipment. The magnetic field generated from the substation environment is expected to travel inside the equipment box. The parameter of the box that will be structured in the model is the dimension, location, and material of the desired by used. The box could be located at desired substation's environment. Ideally, the box should be located at the lowest magnetic field interference.

Using the calculation model, the size and location of this box can be adjusted to any measurement and could be set to anywhere in the substation environment to suite the user needs. For this particular case, the coordinate of the focus area chosen is located at [102,22,2]. As for the box dimension in the calculated model are set to be $0.5 \mathrm{~m}$ for length, width, wide, and the thickness of the metal box is set to be $0.02 \mathrm{~m}$. The dimension of the box could be changed to any measurement that required fitting the equipment that will install in the substation as illustrated in Fig. 9.

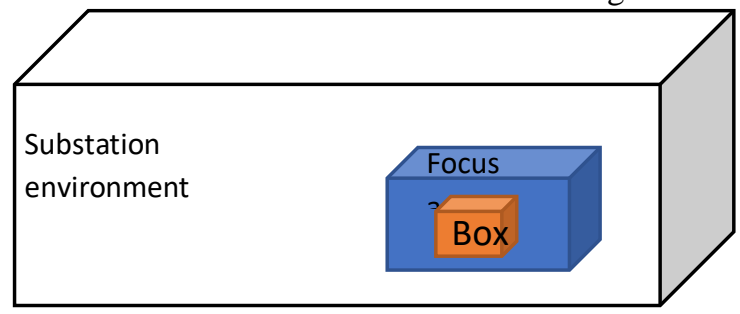

Fig. 9. Illustration of whole substation area and focus area

The same calculation method used, where developed FDM applied to every node in the mesh grid to calculate the magnetic field within the metal box. Fig. 10 shows that the grid or mesh in 2D where the cross-section of the metal box is illustrated. Every node $(\mathrm{i}, \mathrm{j}, \mathrm{k})$ are divided to the region into a number of the subdomain. The blue mesh is set as a focus area which calculated earlier, the grey mesh will be the metal box and the white will be air. All parameter that associate to every node applied to the finite difference equation.

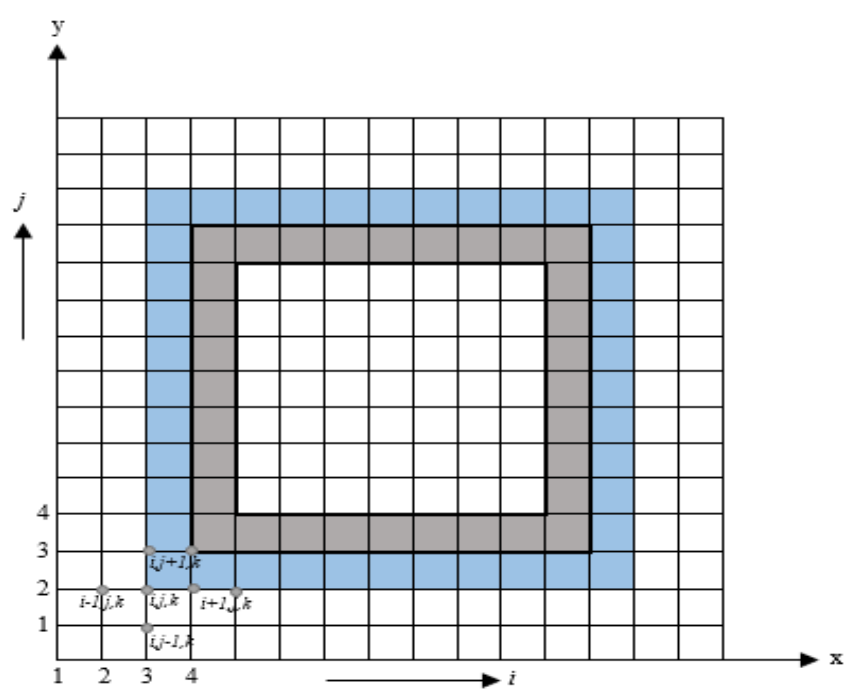

Fig. 10. Finite difference grid or mesh in 2D (crosssection) with a metal box

To illustrate the real equipment that will be installed in the substation environment, the metal box model as the equipment under test should have a cut opening on the surface, which generally for power supply connection or control button. The manufacturer will try to make it as small as possible to avoid any interference propagate into the equipment. Since the source of magnetic field interferences coming from the transmission line above the box, the cut opening on the box is located on the lowest position as illustrated in Fig. 11. The other parameter that needs to be considered is the material, which is the representative in the magnetic field equation as permeability, $\mu$ of material as shown in (13).

With this calculation and prediction of the magnetic field within the operated substation, the result would be useful not only for safety assurance but it also will help utility company to design a newly automated substation or refurbish the old one with an optimum immunity level. The magnetic field generated from the substation environment flowing into the box through the cut opening and it is predicted that the magnetic field has higher field density at the opening of the box, and it will disperse within the area.

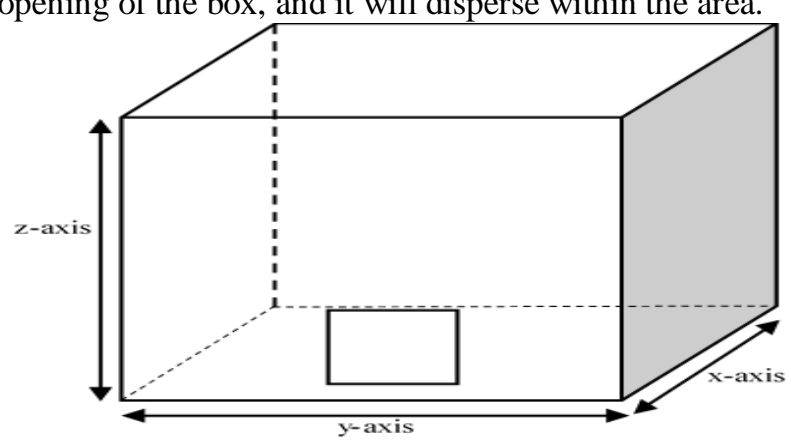

Fig. 11. Illustration of the box with an opening cut

\section{Computational Results and Discussion}

Based on the result of the calculation from the developed algorithm in MATLAB, the magnetic field generated from the substation environment penetrate the box via the opening cut on the model box and the field travelled inside 
the box freely. The magnetic field was calculated for two current and lightning strike into the substation. The result shows the higher field density is located at the opening of the box as plotted in Fig. 12 and 13. Thus, the magnetic field generated from the substation environment able to enter in the box via any size and location of the cut opening on the metal box.

Based on the calculated magnitude of the magnetic field as listed in Table II, the predicted magnetic field during the substation's normal operation is below the safety guidelines exposure limit for health and safety, both public and occupational set by ICNIRP [24], [25] with $0.4 \mathrm{~A} / \mathrm{m}$. In contrast with lightning event apply in the substation system, it shows that it is not fulfilling the recommended limits need to be $0.7 \mathrm{~A} / \mathrm{m}$ in the equipment room, where during the lightning event the magnetic field was calculated to be $854.5 \mathrm{~A} / \mathrm{m}$. Thus, the substation environment is not a safe place for anyone. Nevertheless, the equipment in the substation is included at risk. The compatibility requirement set by IEC61000 [22], [26] within the substation environment needs to be fulfilled.

Table- II: The magnitude of the calculated magnetic field

\begin{tabular}{|l|l|}
\hline Substation Condition & $\overline{\mathbf{H}} \mathbf{( A / m )}$ \\
\hline Normal operation & 0.4323 \\
\hline Lightning & 854.505 \\
\hline
\end{tabular}

Typically, during the lightning event, the protection system in the substation should be operated instantaneously to protect the equipment and component from lightning pulse flowing in. However, the magnetic field generated by this high current might cause electromagnetic compatibility issues in the system [27]. There was more power electronic equipment installed in the Smart Grid system with the latest development of smart grid substation [28], [29]. To ensure the system operate within the optimal compatibility level towards magnetic disturbances, it needs to satisfy the standard requirement by IEC61000 [22], [26]
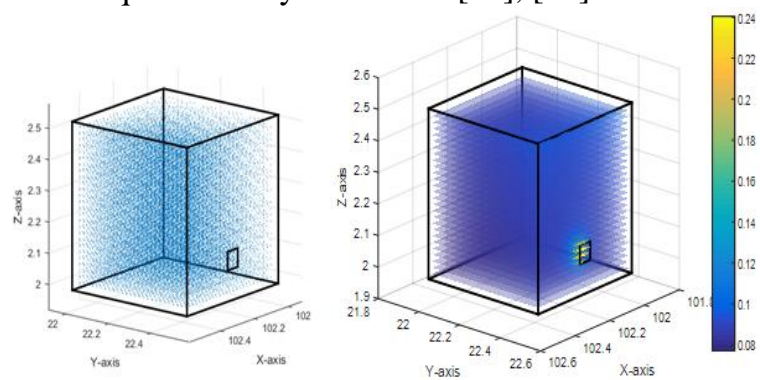

Fig. 12. Magnetic field (A/m) distributed inside the metal box with an opening during normal condition
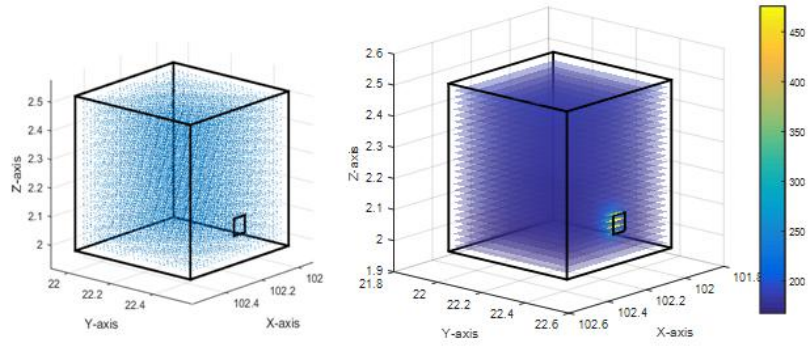

Fig. 13. Magnetic field (A/m) distributed inside the metal box with an opening during lightning different input current, which is during the normal operating

\section{CONCLUSION}

In this paper, the FDM equation has been introduced to calculate the magnetic field in the focus area within the substation environment. In result, the FDM compared with the previous work using BSL as discussed previous work on magnetic field calculation within the substation. With the low percentage differences between both methods show that the calculation method is suitable to predict the magnetic distribution. The combination of both ways helps to achieve optimal simulation routine in predicting the magnetic field in the substation area with any current input. A model of metal box introduces in the simulation to represent the real equipment that will be installed in the focus area of the substation environment. The magnetic field distribution inside the box was calculated using FDM. The computed value is compared with the standard immunity or electromagnetic compatibility level of the equipment and help in the planning of the new equipment installed in the substation environment in future.

\section{ACKNOWLEDGMENT}

The layout of the substation provided by the Technical University of Cluj, Faculty of Electrotechnics, Romania and authors are grateful to Universiti Teknikal Malaysia Melaka for the financial support through Pusat Pengurusan Penyelidikan dan Inovasi (CRIM).

\section{REFERENCES}

1. E. Csanyi. (2012). Smart grid concept and characteristics. [Online]. Available: https://electrical-engineering-portal.com/smart-gridconcept-and-characteristics.

2. A. Duffy and D. Heirman, "Smart grid and EMC standards," IEEE Electromagnetic Compatibility Magazine, vol. 1, no. 4, pp. 97-99, 2012.

3. E. Chikuni, "Power system and substation automation," in Automation, F. Kongoli, Ed London: IntechOpen, pp. 103-130, 2012.

4. Working Group C4.208. (2013). EMC within power plants and substations. [Online]. Available: https://e-cigre.org/publication/535-emc-withinpower-plants-and-substations.

5. S. Bricker, T. Gonen, and L. Rubin, "Substation automation technologies and advantages," IEEE Computer Applications in Power, vol. 14, no. 3, pp. 31-37, 2001

6. U. M. Peterlin and T. Zivic, "Electromagnetic compatibility levels in power plants and substations," IEEE International Symposium on Electromagnetic Compatibility, pp. 266-270, 2015.

7. U. M. Peterlin, "Guidelines for electromagnetic compatibility provision in power plants and substations," International Symposium on Electromagnetic Compatibility, pp. 478-482, 2013.

8. U. M. Peterlin and T. Živic, "Electromagnetic compatibility levels in power plants and substations," IEEE International Symposium on Electromagnetic Compatibility, 2015, pp. 266-270.

9. G. Koepke, "Electromagnetic compatibility and smart grid interoperability issues," Smart Grid Interoperability Panel (SGIP) Electromagnetic 
Interoperability Issues Working Group, 2012.

10. P. F. Keebler, "Meshing power quality and electromagnetic compatibility for tomorrow's smart grid," IEEE Electromagnetic Compatibility Magazine, vol. 1, no. 2, pp. 100-103, 2012.

11. P. Kotsampopoulos, A. Rigas, J. Kirchhof, G. Messinis, A. Dimeas, N. Hatziargyriou, V. Rogakos, and $\mathrm{K}$. Andreadis, "EMC issues in the interaction between smart meters and power electronic interfaces," IEEE Transactions on Power Delivery, vol. 32, no. 2, pp. 822-831, 2016.

12. I. Said, A. S. Farag, H. Hussain, and N. A. Rahman, "Measurement of magnetic field from distribution substations in Malaysia," Australasian Universities Power Engineering Conference, pp. 29-32, 2004

13. W. Lihui, H. Jiayu, J. Jianfei, P. Fubin, and Y. Yubo, "Measurement of transient electromagnetic coupling and interference caused by disconnector operation in substation," Measurement, vol. 96, pp. 1-7, 2017.

14. A. S. Safigianni and C. G. Tsompanidou, "Electricand magnetic-field measurements in an outdoor electric power substation," IEEE Transactions on Power Delivery, vol. 24, no. 1, pp. 38-42, 2009.

15. A. Weddemann, D. Kappe, and A. Hutten, "Hybrid FEM-BEM approach for two- and threedimensional open boundary magnetostatic problems," COMSOL Conference, pp. 1-6, 2011.

16. T. Ling, W. Xiaoyu, Q. Liang, S. Lu, and Y. Fan, "Calculation of power frequency electric field in HV substation using BEM," IEEE Asia-Pacific Power and Energy Engineering Conference, pp. 1-4, 2011.

17. C. P. Nicolaou, A. P. Papadakis, P. A. Razis, G. A. Kyriacou, and J. N. Sahalos, "Experimental measurement, analysis and prediction of electric and magnetic fields in open type air substations," Electric Power Systems Research, vol. 90, pp. 4254, 2012.

18. Y. Ma, G. G. Karady, J. R. Hunt, and B. L. Priest, "Measurement and prediction of electrical substation generated electromagnetic field," IEEE Power and Energy Society General Meeting, pp. 16, 2011.

19. A. S. Safigianni and A. Kostopoulou, "Electric and magnetic field measurements in an indoor electric power substation," Journal of Materials Processing Technology, vol. 181, no. 1-3, pp. 126-130, 2007.

20. A. I. Tarmizi, M. D. Rotaru, and J. K. Sykulski, "Magnetic field calculations within substation environment for EMC studies," IEEE 16th International Conference on Environment and Electrical Engineering, 2016, pp. 1-6.

21. World Health Organization (WHO). (2007). What are electromagnetic fields? Current standards. [Online]. Available: https://www.who.int/pehemf/about/WhatisEMF/en/index4.html.

22. International Electrotechnical Commission (IEC), Electromagnetic compatibility (EMC)-Part 4-8: Testing and measurement techniques-Power frequency magnetic field immunity test. Geneva: IEC, 2010.

23. D. N. Fîta, L. Muresan, C. Cheleman, and M. Grebenisan, "The modelling of Rosiori power station 400/220/20 kV Retechnologized of Transelectrica Company. The simulation of the permanent regime with EDSA programme," 6th International Conference Electromechanical and Power Systems, pp. 317-322, 2007.

24. World Health Organization (WHO). (2007). Electromagnetic fields and public health - Exposure to extremely low frequency fields. [Online].
Available:

http://www.who.int/pehemf/publications/facts/fs322/en/.

25. International Commission on Non-Ionizing Radiation Protection (ICNIRP). (1998). ICNIRP guidelines for limiting exposure to time-varying electric, magnetic and electromagnetic fields (up to 300 GHz). [Online]. Available: http://www.icnirp.org/cms/upload/publications/ICN IRPemfgdl.pdf.

26. Institute of Electrical and Electronics Engineers (IEEE), IEEE standard for power line communication equipment-Electromagnetic Compatibility (EMC) requirements-Testing and measurement methods. New York: IEEE, 2010.

27. S. Gu, D. Li, X. Zeng, J. Su, Y. He, and Z. Zhao, "Analysis of the characteristics and impact of lightning on smart substations," IEEE 5th International Symposium on Electromagnetic Compatibility, 2017, pp. 1-6.

28. Y. Yang, Z. Zhao, S. Gu, D. Li, and X. Zeng, "Analysis of the impact of direct lightning smart substation overhead ground wire on the station smart components," Asia-Pacific International Symposium on Electromagnetic Compatibility, 2016, pp. 927-929.

29. Q. Song, W. Sheng, L. Kou, D. Zhao, Z. Wu, and H Fang, "Smart substation integration technology and its application in distribution power grid," CSEE Journal of Power and Energy Systems, vol. 2, no. 4, pp. 31-36, 2016 